\title{
Social Video Learning with a Blended Learning Framework in German Soccer Trainer Education
}

\author{
https://doi.org/10.3991/ijac.v10i1.6301 \\ Frank Vohle \\ Ghostthinker GmbH, Hamburg, Germany \\ vohledghostthinker.de
}

\begin{abstract}
This Case Study describes a Blended Learning Pilot Scheme with focus on Social Video Learning (SVL) in the context of education for popular sports trainers in the German Football Association. The didactic design provides information on target groups, learning targets and the structuring of the learning environment. Finally, the first evaluation results under the framework of a design-based research study show the positive assessments by students and trainers together with the potential for improvement in the redesign of the next development cycle.
\end{abstract}

Keywords-Social Video Learning, Blended Learning, Trainer Education, Football, Web 2.0, Video Collaboration, Video Annotation, Design-Based Research.

\section{Introduction}

The pilot project is an in-service further training program for the B-License qualification (mid- level training). Two pilot groups were selected to put this into practice: In the Football and Light Athletics Association of Westphalia (FLVW), 23 trainers with an average age of 30 and in the Football Association for the federal state of Sachsen-Anhalt (FSA) 13 trainers with an average age of 26 received further educational training.

The aims of the pilot project can be summarized as follows: (1) Planning, implementation and evaluation of Blended Learning courses with the method focus on Social Video Learning, (2) focus on design and collaboration-oriented tasks in the online phases for the furtherance of trainer competence in technical-tactical perception and reflection.

\section{Target Group and Aims}

The pilot project is an in-service further training program for the B-License qualification (mid- level training). Two pilot groups were selected to put this into practice: In the Football and Light Athletics Association of Westphalia (FLVW), 23 trainers with an average age of 30 and in the Football Association for the federal state of 
Sachsen-Anhalt (FSA) 13 trainers with an average age of 26 received further educational training.

The aims of the pilot project can be summarized as follows: (1) Planning, implementation and evaluation of Blended Learning courses with the method focus on Social Video Learning, (2) focus on design and collaboration-oriented tasks in the online phases for the furtherance of trainer competence in technical-tactical perception and reflection.

\section{$3 \quad$ Research Strategy}

The pilot schemes initiated at the DFB are oriented to the scientific models of didactic development research and design-based research (Reinmann \& Vohle, 2013). At the center is the development of teaching, learning and testing scenarios that are stable and useful in practice and which are realized through iterative phases of design, test, evaluation and redesign. Problem definition and step-by-step problem solution are undertaken together with the practitioners. At the same time both theory-based procedure and also theory-supporting work are demanded, whereby local design recommendations can be deduced. Fig. 1 (McKenny \& Reeves, 2012, p.77) is the visual representation of how in iterative cycles an increasingly more mature intervention and deeper theoretical discoveries arise.

Against this background of (long-term) research strategy the initial cycle gave rise to the following media-didactic questions: (a) Is this new learning organization (Blended Learning) actively taken up and used by all those involved? (b) Is the method "Social Video Learning" classed as meaningful for the learning objectives to be attained?

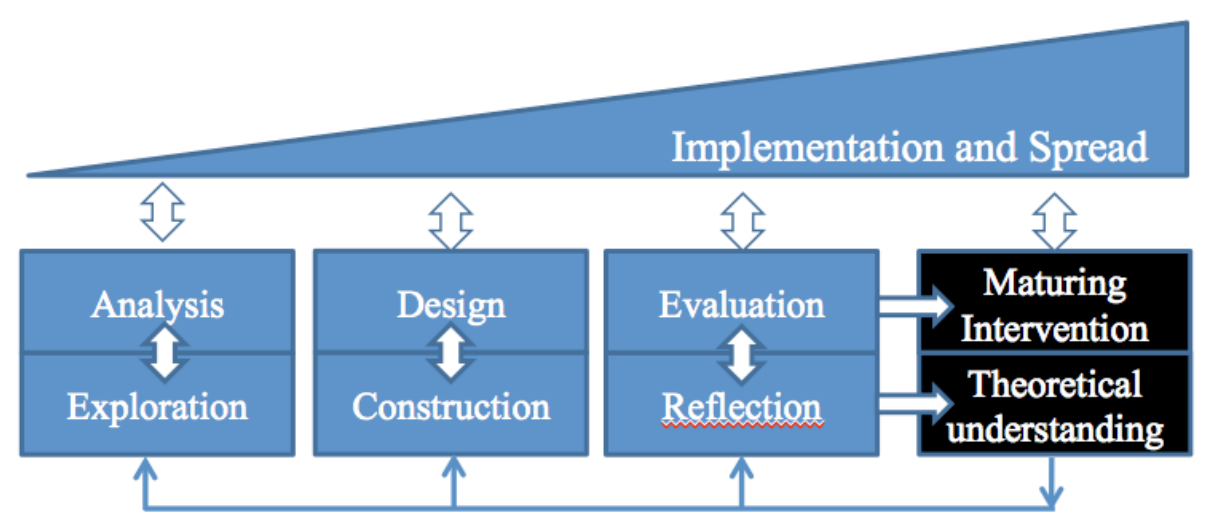

Fig. 1. Visual representation of how in iterative cycles deeper theoretical discoveries arise (McKenny\&Reeves, 2012, p.77 


\section{Didactical Design}

In the following part, because of similarity of structure between the two pilot projects, then only the didactic course design of FLVW is presented here in more detail.

Blended Learning Framework: The fundamental idea for the new study course design was based on retaining the previous scope of 120 learning units à $45 \mathrm{~min}$. (presence), to be allocated to certain times and linked with additional online phases. This gave rise to a Blended Learning Structure with a typical interchange of online and presence phases stretching over 2 months, cf. Fig. 2.

Online-Learning: The online learning phases took place in the edubreak ${ }^{\circledR}$ SPORTCAMPUS (Fig. 3), a learning environment (LMS) with focus on "Social Video Learning" (SVL), developed especially for trainer education in sports (Vohle \& Reinmann, 2014, Vohle \& Reinmann, 2012).

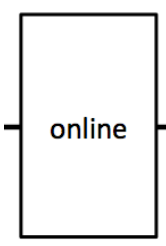

4 davs

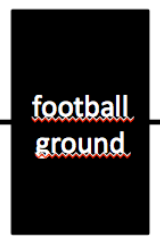

14 davs

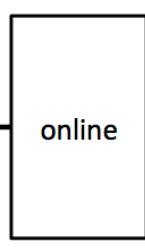

3 days

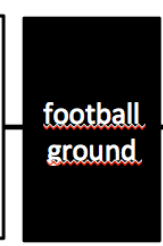

5 days

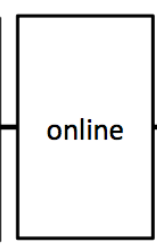

4 days

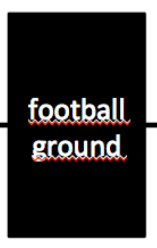

5 davs

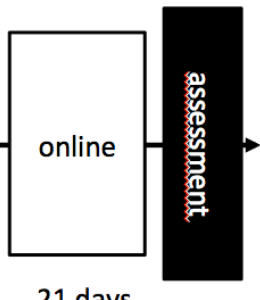

21 davs

Fig. 2. Typical interchange of online and presence phases over two months

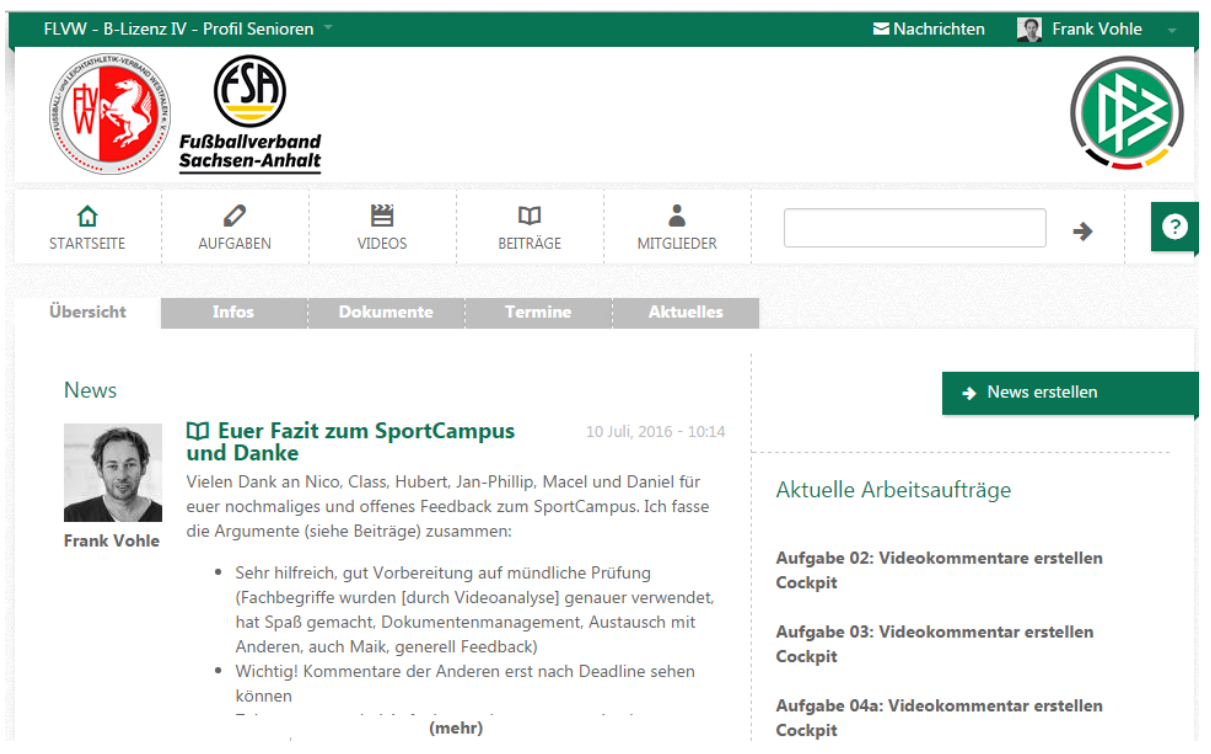

Fig. 3. edubreak ${ }^{\circledR}$ SPORTCAMPUS the webbased online learning environment 
SVL is characterized by two technical-didactical innovations: The first of these is the possibility to comment on videos situation-targeted with text, drawings and symbols or annotations and secondly, by sharing and discussing these video commentaries with others (cf. Pea, Lindgren Rosen, 2008; Krammer \& Reusser, 2005). In figure 4, the video player is seen as filtered with a video commentary and the overview of comments according to participant.

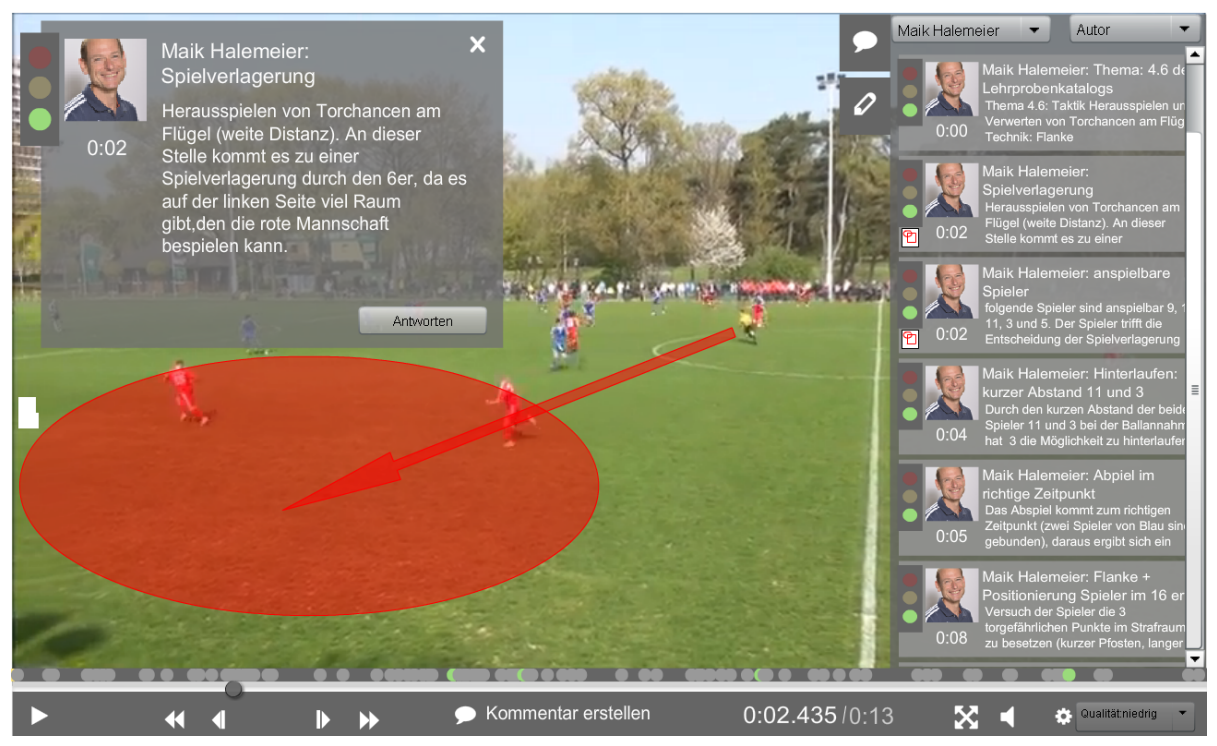

Fig. 4. The edubreak ${ }^{\circledR}$ player enables users to bring in written comments and drawings into the video.

Content Design: The learning aim in the online phases included "game reading", which means recognizing the technical and tactical patterns in the game and also to verbalize with appropriate specialist terms. In support of this interpretation work, videos with football scenes are shown on the contents page.

Interaction design: Through observation tasks, trainers are required to incorporate video commentaries on tactics and techniques in-situ in the videos and to supplement the text comments with a drawing element. In addition the task also involved commenting on the previous video comments of other trainers in a critical and constructive manner.

Supervision design: The didactic design of the course was under the motto: High level management economy! Against the background of this objective the supervision was restricted to motivating and constructive News together with the introduction of expert commentaries (comments by Masters) as an effective form of feedback. The aim was to support the participants to compare their own reflection abilities with expert know-how (self-evaluation). 


\section{$5 \quad$ Empirical Results}

In respect of the current pilot projects at the DFB it can be ascertained that a first cycle is run according to DBR (cf. Paragraph III), in other words, (a) the field was analyzed and explored in cooperation with Practitioners, (b) on a theoretical learning basis (Competence Orientation, Cognitive Tools, Video Reflection) whereby a learning environment with specific tasks for Social Video Learning was drawn up, (c) the Pilot project was carried out and (d) experiences were systematically collated and background aims evaluated. Under this framework of research strategy the following evaluation results can be classified at the same time understood as a "moment record" for the purposes of redesign of learning systems together with content, interaction and supervision design.

Examination design: The Pilot was evaluated in form and sum. In respect of form evaluation, field notes were introduced whereby the Author telephoned every week with the Course Supervisor in order to document problems, to discuss possible solution options and "just in time" implementation. The summarized evaluation comprised an online questionnaire (anonymous) for those taking part with questions about the acceptance of Blended Learning and the use of Social Video Learning. A followon on-line discussion (open) amongst the participants questioned the uses of the Sport Campus and Social Video Learning for the examination passed.

Result 1: The Online Questionnaire showed the following results (4-point scale, here positive and negative responses possible).

\begin{tabular}{|c|c|}
\hline Question & $\mathbf{n}=\mathbf{2 3}$ \\
\hline $\begin{array}{l}\text { Could such a training concept, as you have now learnt it (Mixture of presence phases } \\
\text { and online phases) accord with your personal Time Management? }\end{array}$ & $\begin{array}{l}22 \text { Yes } \\
1 \mathrm{No}\end{array}$ \\
\hline How do you evaluate usability in the Sport Campus? & $\begin{array}{l}23 \text { good } \\
0 \text { bad }\end{array}$ \\
\hline How do you assess the comprehension level for tasks in the learning environment? & $\begin{array}{l}21 \text { good } \\
2 \text { bad }\end{array}$ \\
\hline $\begin{array}{l}\text { Situation-related video commentaries enable the participants to deal more intensively } \\
\text { with the video and observation tasks. Do you agree with this statement? }\end{array}$ & 23 yes \\
\hline $\begin{array}{l}\text { An own perspective of the video content is expanded in that all video comments are } \\
\text { seen after the deadline and then still possible. Do you agree with this statement? }\end{array}$ & $\begin{array}{c}20 \text { yes } \\
3 \text { no }\end{array}$ \\
\hline $\begin{array}{l}\text { The Sport Campus (platform) with focus on video work was developed for Blended } \\
\text { Learning formats in Trainer Education. Has the Sport Campus fulfilled expectations? }\end{array}$ & 23 yes \\
\hline
\end{tabular}

Result 2: In the open online discussion after the final examination the following questions were asked: Did you have the feeling that the Sport Campus (with didactics) had prepared you for your examination? What could we do better in future to improve similar training courses? Six course students took part in this open survey. Three persons classed the course as extremely helpful for the preparation for the oral examination, as "specialist terms are used more precisely by video analysis and interchange with other participants and with the lecturer was possible". As well as this positive evaluation, those taking part also mentioned suggestions for improvement: The video commentary should be viewed only after expiry of the deadline. Time Management of 
the Blended Learning phases was rather inconvenient for those people with jobs as too much had to be processed in too short a time (mostly in the evenings or weekends). The introduction of a grading system should be considered in order to provide a "reward" for services rendered. For the video players the "football-related" drawing tools (e.g. pathways as serpentine lines) should be fine-tuned.

Result 3: Apart from the assessments by participants, this Pilot Project also collated observations and assessments by the lecturer in telephone calls and online meetings. For example, at the beginning of the first "presence phase" the speaker establishes that the "group atmosphere is exceptionally good", as it can be assumed that the participants already know one another before the online phase. He observes that through the writing down of the tasks involved one then has the sensibility for precise instruction, as by means of the video commentaries, it is quickly established whether the core of a set task is understood or not. In the "presence phases" there is a greater "openness for critical dialogue" because the persons taking part see the difference between their layman's perspective (their video commentaries) and the comments of experts. In the end the lecturer assessed the effort-benefit ratio as "good" as with a relatively low level of supervision, "specific points of view" of the participants could be approached which as a rule are not made explicit by those taking part. Social Video Learning thus generates a totally new type of benefit.

\section{Conclusion}

When the results of the pilot project in Westphalia are summarized and supplemented with the very similar assessments of colleagues in Saxony-Anhalt then it is ascertained that the planning and implementation of a new teaching course format with Blended Learning and Social Video Learning can be classed as successful (feasibility) and specifically supportive of learning (target-orientation) in the further education of German football trainers. This is indicated by the overridingly positive feedback from the participants in the online survey and the open discussion (with only a few exceptions), together with the field notes of the lecturer including suggestions for improvements in the sense of cyclical further development (Design- Based Research).

\section{$7 \quad$ Acknowledgment}

We express our thanks to the German Football Association (Wolfgang Möbius) for initiation and for financial support for the project and to the Partners Maik Halemeier (FLVW), Dieter Hausdörfer / Benedikt Bernecker (FSA) and Markus Söhngen (TTVN) for their commitment and support in implementation.

\section{$8 \quad$ References}

[1] Krammer, K. \& Reusser, K. (2005). Unterrichtsvideos als Medium der Aus- und Weiterbildung von Lehrpersonen. Beiträge zur Lehrerbildung, 23(1) 35-50. 
IELA Award Winner-Social Video Learning with a Blended Learning Framework in German Soccer...

[2] McKenney, S. \& Reeves, C.T. (2012). Conducting educational design research. New York: Routledge.

[3] Pea, R., Lindgren, R. \& Rosen, J. (2008). Cognitive technologies for establishing, sharing and comparing perspectives on video over computer networks. Social Science Information, 47(3), 353-370. http://diver.stanford.edu/docs pubs/A144 Pea Lindgren Rosen SSI1.pdf https://doi.org/10.1177/0539018408092577

[4] Reinmann, G., Lames, M. \& Kamper, M. (2010). DOSB Bildung und Qualifizierung - ELearning für die Qualifizierung im organisierten Sport. URL: http://www.dosb.de/ fileadmin/fm-dosb/arbeitsfelder/Ausbildung/E-LEARNING_DOSB.pdf (12.03.2015)

[5] Reusser, Kurt (2005): Situiertes Lernen mit Unterrichtsvideos. In: Journal für Lehrerinnenund Lehrerbildung, 2 (2005), pp. 8-18

[6] Vohle, F. \& Reinmann, G. (2014). Social video learning and social change in German sports trainer education. International Journal of Excellence in Education Volume 6 issue 2. pp 1-11. https://doi.org/10.12816/0010834

[7] Vohle, F. \& Reinmann, G. (2011). Sportschule - Fahrschule - Hochschule? Lehren lernen mit Videoreflexion. In U. Dittler (Hrsg.), E-Learning: Einsatzkonzepte und Erfolgsfaktoren des Lernens mit interaktiven Medien (pp. 175-190). München: Oldenburg

[8] Vohle, Frank (2009): Cognitive tools 2.0 in trainer education. In: International Journal of Sports Science and Coaching, 4 (2009), p. 583 https://doi.org/10.1260/17479 5409790291367

\section{$9 \quad$ Author}

F. Vohle is Founder and Managing Director at the EdTech-Company Ghostthinker GmbH, Hamburg, Germany (vohle@ghostthinker.de).

This work is an IELA Award Winner. Article submitted 26 September 2016. Published as resubmitted by the author 20 December 2016 . 